\title{
Mutant p53 Activator COTI-2
}

National Cancer Institute

\section{Source}

National Cancer Institute. Mutant p53 Activator COTI-2. NCI Thesaurus. Code C121951.

An orally available third generation thiosemicarbazone and activator of mutant forms of the p53 protein, with potential antineoplastic activity. Upon oral administration, mutant p53 activator COTI- 2 targets and binds to the misfolded mutant forms of the p53 protein, which induces a conformational change that normalizes p53 and restores its activity. This induces apoptosis in tumor cells in which the p53 protein is mutated. In addition, COTI-2 inhibits the activation of Akt2 and prevents the activation of the $\mathrm{PISK} / \mathrm{AKT} / \mathrm{mT}$ OR pathway, thereby inducing apoptosis in cancer cells in which this pathway is overexpressed. p53, a tumor suppressor protein, plays a key role in controlling cellular proliferation and survival. High levels of mutant p53 are seen in many cancers and are associated with uncontrolled cellular growth. 